\title{
Postoperative interstitial brachytherapy in eyelid cancer: long term results and assessment of Cosmesis After Interstitial Brachytherapy scale
}

\author{
Sarbani Ghosh Laskar, MD, DNB', Trinanjan Basu, MD', Suresh Chaudhary, MSc², Devendra Chaukar, MSc³, \\ Mandar Nadkarni, MSc ${ }^{4}$, Manjunatha GN, MD' \\ 'Department of Radiation Oncology, Tata Memorial Hospital, ${ }^{2}$ Department of Medical Physics, Tata Memorial Hospital, ${ }^{3}$ Department of \\ Surgical Oncology, Tata Memorial Hospital, ${ }^{4}$ Department of Head and Neck Surgery, Kokilaben Dhirubai Ambani Hospital, Mumbai, India
}

\begin{abstract}
Purpose: To analyse feasibility and safety of postoperative interstitial brachytherapy (IBRT) in patients of eyelid cancer treated primarily by surgical excision.

Material and methods: In this series, 8 patients with eyelid cancer were treated using postoperative interstitial brachytherapy. Patients were followed up for local control, cosmetic outcome, and acute and late toxicities. Cosmetic outcome was measured using a 6 point indigenous Cosmesis After Interstitial Brachytherapy (CAIB) scale.

Results: The patients were between 23-82 years (median: 71 years). There were 3 females and 5 males, and 3 patients had lesions in upper eyelid. Postoperative high-dose-rate brachytherapy was used in all with 2 catheters implanted in most of them (6 out of 8). Local control was calculated from end of treatment to last follow-up. At last follow-up, all patients remained locally controlled. Two patients had nodal recurrence 6 months after interstitial brachytherapy and were salvaged effectively by external beam radiotherapy. At last follow-up, 7 patients were loco-regionally controlled and one was lost to follow up. All patients had Radiation Therapy Oncology Group (RTOG) grade 1 acute toxicity and 2 had grade 1 Common Terminology Criteria for Adverse Events (CTCAE) version.3 late toxicities. The cosmesis score for the whole group ranged between 0-1 indicating excellent to very good cosmesis.

Conclusions: Postoperative high-dose-rate brachytherapy resulted in excellent disease control and cosmesis without significant acute or late toxicities. It is an effective modality for treatment of eyelid cancers in selected patients. Future prospective studies with the validation of CAIB scale would give us more insight to this effective yet often ignored modality of IBRT.
\end{abstract}

Key words: brachytherapy, cosmesis, eyelid cancer, toxicities.

\section{Purpose}

Cancer of the eyelid accounts for $5-10 \%$ of all skin cancers with $90 \%$ being basal cell carcinoma (BCC) [1]. Post-operative radiotherapy is usually indicated depending upon the presence of high-risk features for recurrence [2]. Positive surgical margins in primary BCC excisions in the head and neck region were reported to be $3-20 \%$ in the literature and recurrence rates in incompletely excised patients were reported at $26-67 \%$ as well [3]. Among the Indian population, squamous and adenocarcinoma involving tarsal glands are more common, incidence ranging between $2.4 \%$ to $30.2 \%$ of all malignant eyelid tumours in various literatures [4]. They are more aggressive and invasive than basal cell carcinoma, and have a definite metastatic potential. If treatment is delayed, they can invade the orbital and intracranial structures, and hence have a considerable potential for mortality and morbidity [5]. Sebaceous carcinoma tends to affect patients at older age, mostly around fifth decade, with a female preponderance. They arise from the Meibomian glands of the eyelid and have a local recurrence rate around 30\% including invasion of orbital contents and distant metastasis in $20 \%$ cases [5]. Traditionally, surgical excision has been the mainstay of treatment in this group of patients. Moh's micrographic surgery, cryosurgery, laser excision have been used with 5 year control rates in the range of $90 \%$. Radiotherapy, mostly as external beam radiation is added in cases having high chances of local recurrence such as lymph nodal involvement, positive or close margin, perineural invasion, and poorly differentiated tumours [6,7]. The major hindrance in application of

\footnotetext{
Address for correspondence: Sarbani Ghosh Laskar, MD, DNB, Prof., Department of Radiation Oncology, Received: 21.07.2014 Tata Memorial Hospital, Parel, Mumbai, E Borges Marg, Mumbai 400020, India, phone: +91 9820834386, Accepted: 28.09.2014 
post-operative external beam radiotherapy (EBRT) is the close association of vital structures of the globe and the thin skin around the eyelid [7]. Radiation-induced ocular morbidity encompasses a spectrum from transient eyelid erythema to complete loss of vision, with or without loss of the globe [8-10]. Post-operative adjuvant interstitial brachytherapy (IBRT) has been infrequently used for the treatment of eyelid malignancies [11]. In the presence of high risk factors warranting adjuvant radiotherapy, most of the patients receive EBRT, which has its own shortcomings. Post-operative adjuvant high-dose-rate (HDR) brachytherapy can be considered as an effective option in this group of patients for maintaining local control, while preserving cosmesis and function.

We present a series of 8 patients who received postoperative HDR brachytherapy (HDR IBRT) in our hospital. This study aims at proposing an effective alternative for preserving function and cosmesis among eyelid cancer patients, warranting adjuvant radiotherapy after primary excision while maintaining disease control.

\section{Material and methods}

Between August 2007 and July 2012, 8 patients of eyelid cancer receiving post-operative HDR IBRT were analysed. There were 5 male and 3 female patients with age between 23-82 years. All of them underwent primary surgery in the form of wide excision followed by appropriate reconstruction. The initial tumour region was assessed clinically. Appropriate regional nodal dissection was carried out where necessary (parotid and/or neck). The disease was staged by American Joint Committee on Cancer (AJCC) $6^{\text {th }}$ edition of TNM staging. The patient characteristics (demographics) are described in Table 1. Patients were planned for post-operative HDR IBRT after complete wound healing. The implant procedure was carried out under general anaesthesia. The tumour volume (post-operative target volume for brachytherapy) was based on the initial extent of disease and post-operative scar. The irradiated volume included the primary disease extent with a margin of 3-5 mm with modifications if required. Plastic tube technique was used for interstitial implant. In all patients, a single plane interstitial implant was carried out. Sixteen gauge stainless steel needles were used with appropriate spacing between them. Plastic tubes were then threaded through these needles and left in place after removal of the stainless steel needles. Plastic tubes were then secured, opposing the skin by means of plastic buttons and plastic beads (Fig. 1). During treatment, a custom made conformer was fashioned out of dental prosthesis material to prevent additional dose spillage to normal eyes. Image acquisition for brachytherapy treatment planning was done using a dedicated CT simulator. Images were acquired using the GE system light speed CT simulator (GE Health Care, Milwaukee, WI, USA) with patients in supine position with slice thickness of 1-1.5 mm. The brachytherapy planning was done using Nucletron Plato Sunrise V 14.3.1 computerized treatment planning system (Nucletron, an Elekta company, Elekta AB, Stockholm, Sweden). Optimization was done along dose points specified at a distance of
2-3 $\mathrm{mm}$ from the catheters depending on thickness of tumour bed. In the case of single wire implant, dose prescription point of $2 \mathrm{~mm}$ was selected as per the American Association of physicist in Medicine (AAPM) Task Group (TG) report no. 60 [12]. With two parallel implant wires, the dose prescription was followed as per Paris system recommendation [13]. The 85 or $100 \%$ isodose lines were used as reference isodose based on the adequacy of tumour bed coverage and the dose to normal structures like skin and cornea (Fig. 1).

Fractionated high-dose-rate brachytherapy was administered using single high activity Ir-192, as radio-active source with predetermined time at various dwell positions which were $2.5 \mathrm{~mm}$ apart. Total dose was between 21 Gy in 7 fractions to 35 Gy in 10 fractions, respectively. The details of brachytherapy procedures are also highlighted in Table 1. After treatment completion, the tubes were removed under aseptic condition. No procedural complications were noted. During daily treatment (twice daily fractionation with gap of 6-8 hours between them), local anaesthetic was sprayed over the treatment region, antibiotic ointment dressing was carried out, and patients were kept on oral analgesics and if required intravenous Tramadol ${ }^{\circledR}$ as well.

All the 8 patients were reviewed weekly for one month to document acute radiation reactions, 3 monthly for 2 years, and then 6 monthly up to 5 years, then annually once. One patient was lost to follow up after completion of treatment. On follow-up, patients were examined

Table 1. Demographics of IBRT patients

\begin{tabular}{|c|c|}
\hline Age & $\begin{array}{l}\text { Median: } 71 \text { years } \\
\text { Range: } 23-82 \text { years }\end{array}$ \\
\hline Gender & $\begin{array}{l}\text { Male: } 5(62.5 \%) \\
\text { Female: } 3(37.5 \%)\end{array}$ \\
\hline Diagnosis & $\begin{array}{l}\text { Sebaceous carcinoma: } 4 \text { (50\%) } \\
\text { Squamous cell carcinoma: } 3 \text { (37.5\%) } \\
\text { Basal cell carcinoma: } 1 \text { (12.5\%) }\end{array}$ \\
\hline Site & $\begin{array}{l}\text { Upper eyelid: } 3(37.5 \%) \\
\text { Lower eyelid: } 5 \text { (62.5\%) }\end{array}$ \\
\hline T stage & $\begin{array}{l}\text { T4: } 3(37.5 \%) \\
\text { Other than T4: } 5 \text { (62.5\%) }\end{array}$ \\
\hline $\begin{array}{l}\text { Other histopathological } \\
\text { features }\end{array}$ & $\begin{array}{l}\text { Tumor size: } 4-15 \mathrm{~mm} \\
\text { Median tumor size: } 11 \mathrm{~mm} \\
\text { LVI: negative }(8 / 8) \\
\text { PNI: positive }(1 / 8) \\
\text { Cut margin: } \\
\quad \text { close } 3(37.5 \%) \\
\quad \text { negative } 5(62.5 \%)\end{array}$ \\
\hline Post op IBRT & $\begin{array}{l}\text { Dose range: } 3-3.5 \text { Gy (per fraction) } \\
\text { Fractions: } 7-10 \\
\text { Number of catheters: } 1-2 \\
\text { Treatment time: } \\
\quad 46.2 \text { sec. (median) } \\
\quad 4.8-62.6 \text { sec. (range) }\end{array}$ \\
\hline Follow up months & Median: 34.5 months \\
\hline DFS months & $\begin{array}{l}\text { Median: } 34.5 \text { months } \\
\text { Range: 0-75 months }\end{array}$ \\
\hline
\end{tabular}



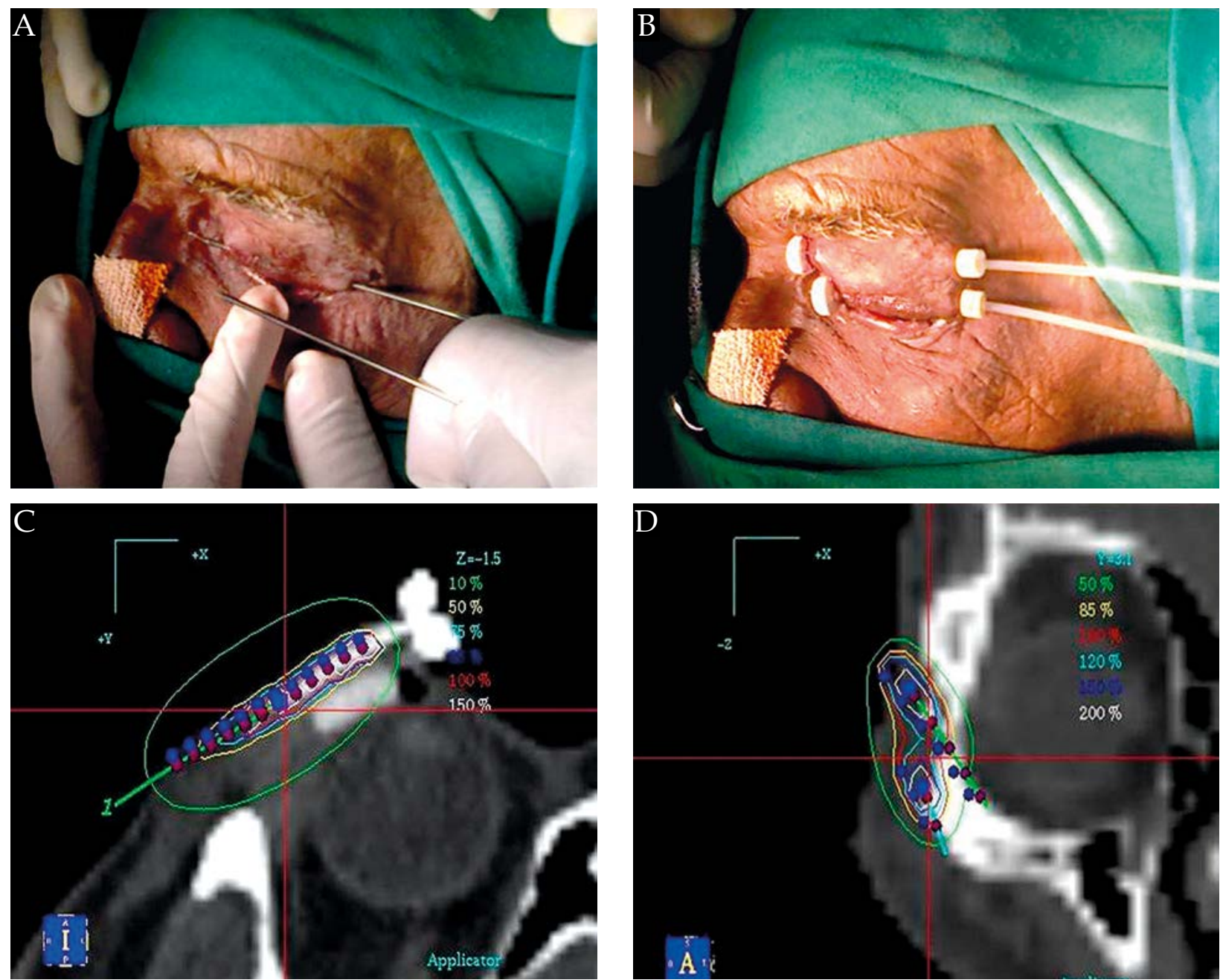

Fig. 1. Postoperative IBRT in eyelid cancer-planning and dosimetry

clinically as well as with ophthalmologic evaluation as warranted. The status of these patients pertaining to disease control was done by clinical examination of both the primary site and neck. At certain intervals it was supplemented by detailed ophthalmologic examination, which also took care of toxicity assessment.

Any visual deterioration and complications pertaining to skin over eyelid, conjunctiva, and overall cosmesis were looked for. Acute toxicities were graded by RTOG acute toxicity scale and CTCAE version 3 criteria were used for late complications pertaining to skin, eyelid, and vision, respectively. Cosmesis was graded and documented using a 6 domain objective scoring criteria. The indigenous CAIB scale was designed keeping in mind the different ocular structures and their late effects viz. depigmentation of skin, eyelid dysfunction like ectropion or entropion, dry eye, keratitis, cataract, and glaucoma. If present, they were scored as 1 and 0 if they were absent. On a total score between $0-6,4$ groups were made with score 0 being excellent cosmesis, scores 1-2 as very good, 3-4 as fair, and scores 5-6 as poor cosmesis. This scale was specifically devised with responses yes/no to actually document effectiveness of HDR IBRT in terms of cosmetic outcome (Table 2).

\section{Results}

All 8 patients completed their treatment. The median follow-up duration was 35 months. Three patients had upper eyelid tumour, while 5 had tumours in lower eyelid. Four patients had sebaceous carcinoma, while 3 had squamous cell carcinoma and 1 patient had a nodular basal cell carcinoma. The acute toxicities were graded by RTOG acute toxicity criteria. All the 8 patients had grade 1 acute reactions, either faint erythema (6 patients) or mild epiphora (2 patients). The late toxicities that we looked at were the skin of the eyelid in terms of pigmentary changes, eyelid in terms of dysfunction like ectropion or trichiasis, and visual complaints such as cataract, glaucoma and keratitis. Only 2 patients had late toxicity in terms of pigmentory changes persisting over skin of right upper eyelid and mild ectropion. One of the patients was lost to follow up and no comment could be made upon late toxicity or cosmesis. There was no incidence of corneal ulcer, conjunctival foreign body sensation, corneal perforation and cataract, which are of significant concern with EBRT. Acute and late toxicities are summarized in Table 3. The dosimetric analysis of the organs at risk in vicinity to eyelid cancer like remaining uninvolved eyelid, cornea, lens, and lacrimal gland were 
carried out. The maximum dose $\left(D_{\max }\right)$ received to these structures was noted. The $\mathrm{D}_{\max }$ for uninvolved eyelid was 17.2 Gy, for cornea 6.7 Gy, lens received 1.9 Gy and lacrimal gland on the ipsilateral side $3.4 \mathrm{~Gy}$, respectively. These details are also elaborated in Table 4.

Cosmesis was documented as per the objective CAIB scoring criteria indicated excellent (5 patients) to very good (2 patients) cosmesis. All patients were locally controlled at last follow-up. Two patients failed at the node but were salvage effectively and remain controlled at subsequent follow-up.

\section{Discussion}

The three distinct types of eyelid cancers with their variable local and distant invasion rates coupled with surrounding critical visual apparatus have always posed a challenge towards the effective management. While basal cell cancers are locally recurrent, squamous cell carcinomas are more aggressive and invasive, and sebaceous carcinomas also have high distant failure rates [1416]. The therapeutic challenge is to be able to preserve cosmetic and functional results and therefore the goal of therapy would be both tumour control and function preservation $[17,18]$. A variety of approaches are available for the management of skin cancer, including curettage and electrodessication, Mohs' micrographic surgery [19], cryotherapy, surgical resection, and external beam radiotherapy [15]. Radiotherapy is used as adjuvant treatment in high-risk lesions, which include positive margins, perineural invasion, and lymph node disease after surgical resection/debulking [6,7].The indications for postoperative radiation include positive surgical margins, perineural spread, invasion of bone and cartilage, extensive skeletal muscle infiltration and poor differentiation $[15,20]$. Recent literature also suggests pathological stage more than pT2 alone warrants postoperative radiotherapy for better survival in eyelid sebaceous carcinomas [21].
Table 2. Cosmesis assessment following IBRT (CAIB scale)

\begin{tabular}{lcc} 
Criteria based on late toxicity & Present & Absent \\
\hline Depigmentation of skin & score 1 & score 0 \\
\hline Eyelid dysfunction & score 1 & score 0 \\
\hline Dry eye & score 1 & score 0 \\
\hline Keratitis & score 1 & score 0 \\
\hline Cataract & score 1 & score 0 \\
\hline Glaucoma & score 1 & score 0 \\
\hline Cosmesis outcome & \multicolumn{2}{c}{ Score } \\
\hline Excellent & \multicolumn{3}{c}{0} \\
\hline Very good & \multicolumn{3}{c}{$1-2$} \\
\hline Fair & \multicolumn{3}{c}{$3-4$} \\
\hline Poor & \multicolumn{3}{c}{$5-6$}
\end{tabular}

Traditional radiotherapy was feared because of acute and late sequelae to the ocular structures. For dry eye to develop, incidence of injury increases from $0 \%$ with doses of $30 \mathrm{~Gy}$ to $100 \%$ after doses $\geq 57$ Gy with conventionally fractionated EBRT [9]. The eyelid also develops transient erythema at doses of $30 \mathrm{~Gy}$, with telangiectasia and loss of eye lashes beginning to occur at $40 \mathrm{~Gy}$. Late squeal like ectropion and entropion are noted if EBRT doses exceed $50 \mathrm{~Gy}$. Chances of corneal perforation increase when the cornea receives EBRT dose in excess of $60 \mathrm{~Gy}$. Cataract is a well-known radiation complication presenting as posterior sub capsular opacification. In general, latency and frequency of cataract is a function of radiation dose and conventionally fractionated EBRT dosage exceeding 12 Gy is held responsible [9]. The complications in inner eye structures like retina and optic nerve is primarily deter-

Table 3. Toxicities with IBRT

\begin{tabular}{|c|c|c|c|c|c|c|c|}
\hline Patient no. & $\begin{array}{c}\text { Acute toxicity } \\
\text { worst grade } \\
\text { (RTOG) }\end{array}$ & $\begin{array}{l}\text { Acute toxicity } \\
\text { worst type } \\
\text { (RTOG) }\end{array}$ & $\begin{array}{l}\text { Late toxicity } \\
\text { - skin }\end{array}$ & $\begin{array}{l}\text { Late toxicity } \\
\text { - eyelid }\end{array}$ & $\begin{array}{l}\text { Late toxicity } \\
\text { - visual }\end{array}$ & $\begin{array}{l}\text { Cosmesis } \\
\text { score }\end{array}$ & $\begin{array}{c}\text { Cosmetic } \\
\text { result }\end{array}$ \\
\hline 1 & Grade 1 & $\begin{array}{c}\text { Faint } \\
\text { erythema }\end{array}$ & Grade 0 & Grade 0 & Grade 0 & 0 & Excellent \\
\hline 2 & Grade 1 & Mild epiphora & Grade 0 & Grade 1 & Grade 0 & 1 & Very good \\
\hline 3 & Grade 1 & $\begin{array}{c}\text { Faint } \\
\text { erythema }\end{array}$ & Grade 0 & Grade 0 & Grade 0 & 0 & Excellent \\
\hline 4 & Grade 1 & $\begin{array}{c}\text { Faint } \\
\text { erythema }\end{array}$ & Grade 0 & Grade 0 & Grade 0 & 0 & Excellent \\
\hline 5 & Grade 1 & Mild epiphora & Grade 1 & Grade 0 & Grade 0 & 1 & Very good \\
\hline 6 & Grade 1 & $\begin{array}{c}\text { Faint } \\
\text { erythema }\end{array}$ & Grade 0 & Grade 0 & Grade 0 & 0 & Excellent \\
\hline 7 & Grade 1 & $\begin{array}{c}\text { Faint } \\
\text { erythema }\end{array}$ & Grade 0 & Grade 0 & Grade 0 & 0 & Excellent \\
\hline 8 & Grade 1 & $\begin{array}{c}\text { Faint } \\
\text { erythema }\end{array}$ & NK & NK & NK & 1 & Unknown \\
\hline
\end{tabular}

NK - not known 
Table 4. Dosimetric parameters of eyelid brachytherapy

\begin{tabular}{lccc} 
Organs at risk & Maximum dose $\left(\mathrm{D}_{\max }\right)$ & Range of dose received & Median of $\mathrm{D}_{\max }$ \\
\hline Normal eyelid & $17.26 \mathrm{~Gy}$ & $7.5-17.26 \mathrm{~Gy}$ & $17.22 \mathrm{~Gy}$ \\
\hline Cornea & $6.7 \mathrm{~Gy}$ & $0.98-6.7 \mathrm{~Gy}$ & $1.84 \mathrm{~Gy}$ \\
\hline Lens & $1.9 \mathrm{~Gy}$ & $0.83-1.9 \mathrm{~Gy}$ & $1.27 \mathrm{~Gy}$ \\
\hline Ipsilateral lacrimal gland & $3.4 \mathrm{~Gy}$ & $0.96-3.4 \mathrm{~Gy}$ & $2.1 \mathrm{~Gy}$
\end{tabular}

mined by the total radiation dose. None of the patients receiving a dose of $<50$ Gy developed optic neuropathy or chiasm injury [10]. In contrast, the 10-year actuarial incidence of optic nerve-chiasm injury was $\sim 5 \%$ for patients receiving 50-60 Gy [10] (Table 5). The current literature with postoperative IBRT showed promise with organs at risk (OAR) receiving dosage much lower than that can cause complications.

When EBRT is used in postoperative setting effects such as atrophy, telangiectasia, pigment changes, and other potential complications like tissue necrosis and wound breakdown, have been observed in about $2 \%$ of the patients treated [22]. Late effects include dry eye, hypopigmentation, skin atrophy, cataracts, radiation keratopathy, optic neuropathy, and retinopathy. The incidence of these complications depends on the location and size of the tumour, radiation doses delivered fractionation, and volume of treated areas [16].

Brachytherapy with HDR has several advantages. Being extremely conformal and targeting only the tumour bed, it can spare considerable amount of normal tissue. Also, an equivalent dose can be delivered over a shorter period of time. The total radiation dose delivered ranges from 26 to $63 \mathrm{~Gy}$ in various literatures (median: 60 Gy) [15]. In our study, 21 Gy in 7 fractions to $30 \mathrm{~Gy}$ in 10 fractions was used depending upon the indication. The low dose rate (LDR) equivalent dose was calculated by standard linear-quadratic (LQ) model delivered at $0.5 \mathrm{~Gy} / \mathrm{hr}$. This translates to a LDR dose range of $27 \mathrm{~Gy}$ to $39 \mathrm{~Gy}$. For tumour and acute reacting tissues, the biological equivalent dose (BED) was kept around 40 Gy (with $\alpha / \beta$ ratio kept at 10 ) and that for late reacting tissues around $60 \mathrm{~Gy}$ (with $\alpha / \beta$ of 3 ). One of the larger series with basal cell carcinomas that were more than $2 \mathrm{~cm}$ in dimension has reported EQD2 around 54 Gy for adequate local control [2].
There have been no comparisons between postoperative brachytherapy and postoperative external beam radiation for eyelid cancer in literature, and there is unlikely to be such a study due to the rarity of such cases. Retrospective data with properly documented outcomes would be important in evaluating optimum treatment modalities. There is only one study which compared surgery versus brachytherapy alone. The study population was mostly of basal cell carcinoma. The study indicated slightly better loco-regional control by surgery, but also highlighted the cosmetic deformity by surgery specially in cases of flap reconstructions [23]. Reports on postoperative brachytherapy for eyelid cancer are extremely sparse in literature. Most of the series had mixed populations in terms of both histology (squamous and basal cell) and type of brachytherapy (radical and postoperative). One large series of peri-orificial skin cancer by Emmanuel et al. has reported 7 cases of postoperative eyelid cancer treated by brachytherapy amongst a total of 97 cases. None of them had major long term sequel. The cosmesis and functional outcomes were graded on a 4 point scale namely anatomic deformity, telangiectasia, pigmentation disorders, and changes in skin texture (atrophy, folds) [6]. Another recent series reporting interstitial brachytherapy for eyelid cancers with basal and squamous cell carcinomas reported very high local control rates (> 95\%) after almost 8 years median follow up and also acceptable cosmetic outcomes [24]. Kowalik et al. have tried to use individual applicator for different disease sites in the head and neck region, and one of their cases had a recurrence of squamous cell cancer at root of nose close to eyes. They have also showed excellent results in treating these recurrences. To re-emphasise, brachytherapy techniques seem to be the most effective and easy treatment to protect organs located deeper than $2 \mathrm{~cm}$ below the surface, and from the perspective of protecting critical healthy organs

Table 5. Early and late effects of radiation on ocular structures

\begin{tabular}{lcc}
\hline \multicolumn{1}{l}{ Structure } & \multicolumn{1}{c}{ Early effects } & Late sequel \\
\hline Eyelid & Erythema, telengiectasia, loss of eye lashes & Trichiasis, ectropion, entropion \\
\hline Lacrimal system & Dry eye, burning sensation in eyes & Atrophy, stenosis of NLD \\
\hline Conjunctiva & Conjunctivitis & Conjunctival scarring \\
\hline Cornea & Keratitis, corneal ulcer & Corneal perforation \\
\hline Lens & & Cataract \\
\hline Retina and optic nerve & Macular edema, transient visual loss & Optic neuropathy
\end{tabular}


as well. However, it demands technical expertise in these cases [25].

Our study in comparison to available literature also showed an excellent local control with a median follow up of 4 years. The indigenous yet to be validated CAIB scale, taking into considerations the important late toxicities in the ocular structures was found to be quite useful both in terms of applicability and accuracy. The small sample size and heterogeneous population of eyelid cancer patients actually highlight the rarity of such cases and treatment approach like postoperative HDR IBRT. The CAIB scale used in our study showed excellent to very good cosmesis in all cases.

\section{Conclusions}

Adjuvant HDR brachytherapy in patients of eyelid cancer undergoing primary surgical excision is safe and efficacious. The small numbers in the series reflect the low incidence of this cancer in our part of the world, but the results prove that effective adjuvant therapy can be provided when necessary with very good disease control and functional outcomes. The indigenous CAIB scale with future prospective validation studies would definitely streamline management of this rare disease with acceptable cosmetic outcomes.

\section{Acknowledgments}

We wish to sincerely thank all our colleagues and staffs who helped us while preparing this manuscript. Here, we would like to specially mention the immense contribution made by Dr Siddhartha Laskar, Professor, Department of Radiation Oncology, Tata Memorial Hospital, Mumbai, India. We sincerely acknowledge his effort in all the phases of this study starting from methodology to evaluation of cosmesis. All the authors whose work guided and inspired us need special mention. Finally, gratitude to our ailing patients whose suffering has always been a key motivating factor behind this study.

\section{Disclosure}

Authors report no conflict of interest.

\section{References}

1. Cook BE Jr, Bartley GB. Treatment options and future prospects for the management of eyelid malignancies: an evidence based update. Ophthalmology 2001; 108: 2088-2098.

2. Khan L, Breen D, Zhang L et al. Predictors of recurrence after radiotherapy for non-melanoma skin cancer. Curr Oncol 2014; 21: 326-329.

3. Demirseren DD, Ceran C, Aksam B et al. Basal cell carcinoma of the head and neck region: a retrospective analysis of completely excised 331 cases. J Skin Cancer 2014; 2014: 858636

4. Dailey JR, Kennedy RH, Flaharty PM et al. Squamous cell carcinoma of eyelid. Ophthal Plast Reconstr Surg 1994; 10: 153-159.

5. Azad S, Choudhary V. Treatment results of high dose rate interstitial brachytherapy in carcinoma of eye lid. J Cancer Res Ther 2011; 7: 157-161.
6. Rio E, Bardet E, Ferron C et al. Interstitial brachytherapy of periorificial skin carcinomas of the face: a retrospective study of 97 cases. Int J Radiat Oncol Biol Phys 2005; 63: 753-757.

7. Lederman M. Radiation treatment of cancer of the eyelids. $\mathrm{Br}$ J Ophthalmol 1976; 60: 794-805.

8. Gordon KB, Char DH, Sagerman RH. Late effects of radiation on the eye and ocular adnexa. Int J Radiat Oncol Biol Phys 1995; 31: 1123-1139.

9. Parsons JT, Bova FJ, Fitzgerald CR et al. Severe dry-eye syndrome following external beam irradiation. Int J Radiat Oncol Biol Phys 1994; 30: 775-780.

10. Jeganathan VSE, Wirth A, MacManus MP. Ocular risks from orbital and periorbital radiation therapy: A critical review. Int J Radiat Oncol Biol Phys 2011; 79: 650-659.

11. Martinez-Monge R, Gomez-Iturriaga A. High-dose-rate brachytherapy in lower eyelid cancer. Brachytherapy 2007; 6: 227 229

12. Nath R, Amols H, Coffey C et al. Intravascular brachytherapy physics: report of the AAPM Radiation Therapy Committee Task Group no. 60. American Association of Physicist in Medicine. Med Phys 1999; 26: 119-152.

13. Dutreix A, Marinello G, Wambersie A. Dosimetrie en Curietherapie. Masson, Paris 1982.

14. Reifler DM, Hornblass A. Squamous cell carcinoma of the eyelid. Surv Ophthalmol 1986; 30: 349-365.

15. Petsuksiri J, Frank SJ, Garden AS et al. Outcomes after radiotherapy for squamous cell carcinoma of the eyelid. Cancer 2008; 112: 111-118.

16. Murchison AP, Walrath JD, Washington CV. Non-surgical treatments of primary, non-melanomaeyelid malignancies: a review. Clin Experiment Ophthalmol 2011; 39: 65-83.

17. Leventhal HH, Messer RJ. Malignant tumors of the eyelid. Am J Surg 1972; 124: 522-526.

18. Conill C, Sanchez-Reyes A, Molla M et al. Brachytherapy with 192Ir as treatment of carcinoma of the tarsal structure of the eyelid. Int J Radiat Oncol Biol Phys 2004; 59: 1326-1329.

19. Lawrence CM. Mohs surgery of basal cell carcinoma - a critical review. Br J Plast Surg 1993; 46: 599-606.

20. Malhotra R, Huilgol SC, Huynh NT et al. The Australian Mohs database: periocular squamous cell carcinoma. Ophthalmology 2004; 111: 617-623.

21. Choi YJ, Jin HC, Lee MJ et al. Prognostic value of clinical and pathologic $\mathrm{T}$ stages defined by the American Joint Committee on Cancer foreyelid sebaceous carcinoma in Korea. Jpn J Ophthalmol 2014; 58: 327-333.

22. Hsu A, Frank SJ, Ballo MT et al. Postoperative adjuvant external-beam radiation therapy for cancers of the eyelid and conjunctiva. Ophthal Plast Reconstr Surg 2008; 24: 444-449.

23. Avril MF, Auperin A, Margulis A et al. Basal cell carcinoma of the face: surgery or radiotherapy? Results of a randomized study. Br J Cancer 1997; 76: 100-106.

24. Krengli M, Masini L, Comoli AM et al. Interstitial brachytherapy for eyelid carcinoma. Outcome analysis in 60 patients. Strahlenther Onkol 2014; 190: 245-249.

25. Kowalik L, Lyczek J, Sawicki M et al. Individual applicator for brachytherapy for various sites of superficial malignant lesions. I Contemp Brachytherapy 2013; 5: 45-49. 